\title{
DISTRIBUIÇÃO DA BIOMASSA NO CERRADO E A SUA IMPORTÂNCIA NA ARMAZENAGEM DO CARBONO
}

\author{
DISTRIBUTION OF BIOMASS IN CERRADO AND ITS IMPORTANCE FOR CARBON \\ STORAGE
}

José Guilherme Roquette ${ }^{1}$

\begin{abstract}
RESUMO
O Cerrado ocupa cerca de $24 \%$ do território brasileiro e é caracterizado pela presença de um estrato arbóreo e outro arbustivo, formados praticamente por árvores de porte médio e tortuosas, além de gramíneas. A quantidade de biomassa presente no bioma ainda é pouco conhecida, principalmente devido às suas diferenças fitofisionômicas. O interesse pela quantificação da biomassa vem crescendo junto com o interesse pelo aquecimento global, devido à armazenagem do carbono nas diferentes frações dos vegetais. No Cerrado, estes estudos são particularmente importantes devido a aproximadamente $50 \%$ de seu território já ter sido convertido para outros usos do solo, principalmente agricultura e pecuária. Neste sentido, foram abordados os principais fatores relativos à produção da biomassa vegetal, as características das principais fitofisionomias e os estoques e padrões de distribuição da biomassa e carbono na vegetação, destacando, ainda, as estratégias que podem ser adotadas para sua conservação. Observou-se a carência de estudos dessa natureza, que podem ser associados com sensoriamento remoto e sistemas de informações geográficas para estimativas precisas de biomassa e armazenagem do carbono, com eficiência de custos e tempo. Além disso, políticas públicas devem ser incentivadas para maior conservação do bioma, tendo em vista o potencial econômico dos seus recursos naturais, com importância, principalmente, alimentar, medicinal e turística, sobretudo, para as populações tradicionais do Cerrado.
\end{abstract}

Palavras-chave: bioma brasileiro; mudança do uso do solo; mudanças climáticas; uso sustentável.

\begin{abstract}
Cerrado biome occupies about $24 \%$ of the Brazilian territory and it is characterized by the presence of an arboreal and shrub stratus, which is practically formed by medium height and tortuous trees, besides grass. The amount of biomass present in the biome is still little known, mainly due to its phytophysiognomic differences. The interest for the quantification of biomass has been growing along with the global warming interest, due to the storage of carbon in the different fractions of the plant. In Cerrado, these studies are particularly important because approximately $50 \%$ of their land has already been converted to another land use, mainly agriculture and livestock. In this sense, the main factors related to the production of the plant biomass were approached, the characteristics of the main phytophysiognomies, the stocks and the distribution patterns of the biomass and carbon in the vegetation, highlighting also the strategies that can be adopted for its conservation. The lack of studies of this nature was acknowledged, and it could be associated with the remote sensing and geographic information systems for estimating the biomass and carbon storage accuracy, with cost and time efficiency. In addition, public policies should be encouraged for the conservation of the biome, given the economic potential of its natural resources, especially as source of food, medicine and tourism, mainly for the traditional populations of Cerrado.
\end{abstract}

Keywords: Brazilian biome; land-use change; climate change; sustainable use.

1 Engenheiro Florestal, MSc., Doutorando do Programa de Pós-graduação em Física Ambiental, Universidade Federal de Mato Grosso, Av. Fernando Correa da Costa, 2367, Cidade Universitária, Bloco de Física Ambiental, CEP 78060900, Cuiabá (MT), Brasil. guilhermeroquette@yahoo.com.br

Recebido para publicação em 5/06/2013 e aceito em 15/05/2017

Ci. Fl., v. 28, n. 3, jul. - set., 2018 


\section{INTRODUÇ̃̃O}

A partir de 1979, ano em que foi realizado o primeiro estudo rigoroso a respeito do aquecimento global, conduzido por cientistas da Academia Nacional dos Estados Unidos, começaram a se intensificar as pesquisas e análises objetivando não somente a preservação da biodiversidade de áreas florestais, mas também relacionadas a alterações do clima no planeta (CAMPOS, 2001; SEIFFERT, 2009).

Considerando que a temperatura regula diversos processos de crescimento e desenvolvimento vegetal, Watzlawick (2002) afirma que pequenas variações podem ser capazes de provocar modificações no desenvolvimento dos ecossistemas florestais. Segundo Seiffert (2009), os impactos decorrentes da variação na temperatura global afetarão todo o planeta e poderão comprometer, irremediavelmente, o equilíbrio dos ecossistemas.

Marengo (2006) relata que muitos eventos extremos já são atribuídos às variações climáticas que a Terra vêm sofrendo nos últimos anos, como exemplo: a onda de calor na Europa em 2003, o furacão Catarina no sul do Brasil em 2004, os furacões Katrina, Wilma e Rita no Atlântico Norte em 2005, as secas observadas em 2004, 2005 e 2006, também no sul do Brasil, e a seca na região da Amazônia no ano de 2005. Ainda de acordo com o autor, além desses eventos já observados, o aumento da temperatura atmosférica causará impactos na biodiversidade, no nível dos mares, na saúde, na agricultura e na geração de energia hidrelétrica, como já está ocorrendo no Brasil.

As principais causas do aquecimento global são atribuídas ao acúmulo dos gases metano $\left(\mathrm{CH}_{4}\right)$, óxido-nitroso $\left(\mathrm{N}_{2} \mathrm{O}\right)$, ozônio $\left(\mathrm{O}_{3}\right)$, hidrofluorcarbonos ( $\left.\mathrm{HFCs}\right)$ e dióxido de carbono $\left(\mathrm{CO}_{2}\right)$ na atmosfera, originando o chamado efeito estufa, o qual apresenta evidências científicas cada vez mais fortes apontando as atividades humanas, com seu modelo atual de produção, como um dos fatores principais para seu agravamento (CONSELHO EMPRESARIAL BRASILEIRO PARA O DESENVOLVIMENTO SUSTENTÁVEL, 2002; NISHI, 2005).

O modelo de desenvolvimento adotado pelo Homem tem como característica, historicamente, a supressão da cobertura florestal (THIBAU, 2000; MACHADO, 2008). A derrubada ou queima da vegetação, assim como as intervenções frequentes para o preparo do solo, são responsáveis pela liberação do carbono nos diferentes sistemas de uso da terra, uma vez que tais práticas ocasionam, segundo Arevalo, Alegre e Vilcahuaman (2002), "o rompimento do estado estável do carbono na biomassa, o aumento da velocidade de mineralização da matéria orgânica e, consequentemente, a liberação do carbono que se encontra nos poros do solo".

A vegetação, por meio do processo de fotossíntese, tem a capacidade de fixar $\mathrm{CO}_{2}$ da atmosfera. Esse serviço é particularmente importante no balanço global de carbono, com relevância acrescida face aos pressupostos estipulados para redução dos gases causadores do efeito estufa, assim como ao panorama atual de mudanças climáticas (SCHUMACHER; WISTSCHORECK, 2004). Porém, não se pode considerar a vegetação somente como depósito de carbono, mas também como fonte para a atmosfera, dependendo do propósito e da maneira como é manejada (AREVALO; ALEGRE; VILCAHUAMAN, 2002).

Estudos sobre a biomassa presente em ecossistemas são, de fato, importantes para avaliar a capacidade de armazenamento e potencial de emissão de carbono à atmosfera mediante a supressão da vegetação e modificação do uso do solo. Isto considerando que diferentes tipologias de vegetação possuem características diferenciadas em relação à quantidade de biomassa e aos padrões de sua distribuição.

A capacidade dos ecossistemas em armazenar ou emitir carbono atmosférico é determinada por uma série de variedades de processos físicos, químicos e bióticos atuando em diferentes direções e intensidades. As funções de um ecossistema, assim como sua estrutura e composição, não são imutáveis. A ação do Homem pode influenciar direta ou indiretamente em todos os seus processos, alterando as características dos serviços prestados por estes, dentre os quais se destaca a armazenagem do carbono atmosférico, que contribui para a redução nos níveis de $\mathrm{CO}_{2}$ na atmosfera do planeta (ADUAN; VILELA; KLINK, 2003; SCHUMACHER; WISTSCHORECK, 2004; SILVA et al., 2008).

Dentre os ecossistemas brasileiros, ocupando aproximadamente dois milhões de quilômetros quadrados, encontra-se o bioma Cerrado, que, ao longo do tempo, em virtude do desenvolvimento e ocupação humana, vem sendo eliminado, principalmente, pela mudança do uso da terra para práticas de agricultura e pecuária extensiva (MANTOVANI; PEREIRA, 1998; BRASIL, 1999; ADUAN; VILELA;

Ci. Fl., v. 28, n. 3, jul. - set., 2018 
KLINK, 2003; KLINK; MACHADO, 2005; KRUG et al., 2006; SANO et al., 2008; BRASIL, 2015).

Neste sentido, o objetivo foi realizar uma revisão sobre os estudos de estoques de biomassa vegetal no bioma Cerrado, destacando as particularidades de sua distribuição nas diferentes fitofisionomias e a importância na armazenagem do carbono, além de abordar as estratégias que podem ser adotadas para sua conservação. A revisão esteve delimitada pela busca de referências, tanto clássicas como mais recentes, nas seguintes bases bibliográficas: Agris; Agrobase; Scielo; DDP@/Embrapa; DOAJ, Google Acadêmico; Periódicos Capes; Biblioteca da Universidade Federal de Mato Grosso; além do acervo pessoal. Para a busca foram utilizadas as seguintes palavras-chave e expressões: Cerrado; produção primária; composição e estrutura; biomassa; carbono; mudanças climáticas; uso sustentável (idiomas português e inglês). Após o procedimento exploratório, procedeu-se também a consulta analítica das referências utilizadas naquelas que foram encontradas.

\section{FATORES RELACIONADOS À PRODUÇÃO DE BIOMASSA}

Entende-se por produção primária a quantidade de matéria seca (biomassa seca) produzida por um vegetal ou comunidade de vegetais, sendo esta, maior conforme a capacidade de assimilação de carbono por uma espécie ou espécies que compõem determinada comunidade de plantas durante o processo fotossintético (LARCHER, 2006).

A quantidade de energia solar interceptada e absorvida, a capacidade fotossintética, a respiração, o estágio de desenvolvimento e os fatores edafoclimáticos apresentam influência direta na quantidade de biomassa produzida por um vegetal, havendo produção primária sempre que a taxa fotossintética for maior que a taxa respiratória (LARCHER, 2006; PRADO; CASALI, 2006).

A produção primária compreende todo o conjunto de materiais orgânicos gerados por organismos autótrofos do reino vegetal, sendo que, em florestas, geralmente são estimadas a biomassa viva acima do solo, composta por árvores, arbustos e gramíneas, a biomassa morta acima do solo, composta pela serapilheira, troncos caídos e miscelâneas, e a biomassa abaixo do solo, composta pelas raízes e matéria orgânica do solo (COELHO, 1982; MARTINELLI et al., 1994).

$\mathrm{O}$ estudo da produção primária possui importância principalmente para o entendimento das transferências de energia entre os diferentes níveis tróficos de um ecossistema (MEIRELLES; HENRIQUES, 1992). Entretanto, em virtude do panorama atual de mudanças climáticas, estudos referentes à produção de biomassa em diferentes ecossistemas vêm sendo desenvolvidos visando ao conhecimento do potencial para redução dos gases causadores do efeito estufa, particularmente o dióxido de carbono (SCHROEDER, 1992; HIGUCHI et al., 1998; SANQUETTA, 2002; SOARES; OLIVEIRA, 2002; SOARES; LEITE; GÖRGENS, 2005; PAIXÃO et al., 2006; REZENDE et al., 2006; CORTE; SANQUETTA, 2007; SILVA et al., 2008).

A produtividade primária líquida da vegetação é igual à assimilação total de $\mathrm{CO}_{2}$ que é absorvido pelo processo fotossintético (carboxilação), menos as perdas decorrentes da fotorrespiração (descarboxilação) e respiração em um certo período de tempo, excluindo ainda as partes mortas das plantas (LOPES; LIMA, 2015).

O saldo da assimilação de carbono não é determinado somente pela intensidade das trocas gasosas, mas também pela proporção entre a massa dos órgãos fotossinteticamente ativos e não ativos, pela proporção entre períodos favoráveis e não favoráveis e pela própria eficiência do processo fotossintético, que pode variar bastante entre plantas (PAIVA; OLIVEIRA, 2014).

No Cerrado, podem ser encontradas espécies com diferentes ciclos fotossintéticos, denominadas de plantas C4, plantas CAM e plantas C3, sendo decrescente a eficiência fotossintética, respectivamente (PAIVA; OLIVEIRA, 2014). Essa denominação se deve ao número de carbonos do composto formado durante o ciclo fotossintético, sendo a PGA, com três carbonos, sintetizada pelo maior grupo (C3), o malato, com quatro carbonos, produzido por algumas gramíneas e espécies adaptadas á climas áridos (C4), também presentes no bioma Cerrado, e outro grupo que apresenta outro sistema de fixação de $\mathrm{CO}_{2}$, o metabolismo ácido das crassuláceas (CAM) (REICHARDT; TIMM, 2012).

Além disso, o rendimento líquido da assimilação do carbono também é afetado pela composição e arquitetura da fitomassa formada pela planta, estágio de desenvolvimento de suas partes, e pelos fatores edafoclimáticos, já mencionados anteriormente, que podem alterar o metabolismo vegetal (PAIVA; 
OLIVEIRA, 2014; LOPES; LIMA, 2015).

Os fatores edafoclimáticos estão relacionados com a nutrição orgânica (carbono, oxigênio e hidrogênio, provenientes da atmosfera e da água, via fotossíntese) e nutrição inorgânica (macro e micronutrientes, geralmente provenientes do solo) (PAIVA; OLIVEIRA, 2014). Além desses, outros fatores também possuem grande importância para a produtividade primária, como luz, temperatura, concentração de $\mathrm{CO}_{2}$ e $\mathrm{O}_{2}$ no sistema, salinidade e presença de poluentes e disponibilidade hídrica, que é necessária para o bom funcionamento celular (LOPES; LIMA, 2015).

\section{BIOMA CERRADO E SUAS TIPOLOGIAS VEGETAIS}

O bioma Cerrado abrange diferentes fisionomias de vegetação cujas variações são determinadas, de modo geral, por fatores edáficos e topográficos, como a origem geológica, a profundidade do solo, a drenagem, a presença de concreções no perfil, a profundidade do lençol freático e a textura e fertilidade do solo (ALVIN, 1954; EITEN, 1972; MARIMON JUNIOR; HARIDASAN, 2005; SOARES et al., 2015).

A diversidade de ambientes no Cerrado varia, significativamente, na estrutura horizontal, diferentemente de ambientes como a Floresta Amazônica e Mata Atlântica, que possuem ampla variação de acordo com a estratificação vertical, o que proporciona diversas condições para o estabelecimento de espécies (MACHADO et al., 2004).

O Cerrado brasileiro é considerado um dos hotspots mundiais devido à sua excepcional riqueza biológica, que cobre cerca de $24 \%$ do território nacional. Estimativas apontam que nele podem ser encontradas mais de 6.000 espécies de árvores e 800 espécies de aves, além da grande variedade de peixes, abelhas e outros invertebrados (BRASIL, 1999; 2006; 2007).

Klink e Machado (2005), reunindo informações de diversos autores, relacionaram estimativas ainda maiores sobre a biodiversidade no Cerrado, indicando um total de 7.000 espécies de plantas, 199 espécies de mamíferos, 837 espécies de aves, 180 espécies de répteis, 150 espécies de anfíbios e 1.200 espécies de peixes.

Embora considerado como fator secundário de modificação nas características fisionômicas do Cerrado, a presença do fogo em seus ambientes é um importante fator a ser considerado. O comportamento do fogo influencia as características do ambiente e é determinado pela estrutura, composição e produção primária da comunidade vegetal, sendo sua existência natural indicadora da adaptação destes ambientes à sua ação (ALVIN, 1954; RIBEIRO; HARIDASAN, 1984; MEIRELLES; HENRIQUES, 1992; KAUFFMAN; CUMMINGS; WARD, 1994; CASTRO; KAUFFMAN, 1998; KLINK; MACHADO, 2005; MARIMON JUNIOR; HARIDASAN, 2005; BRASIL, 2007).

A fitofisionomia mais comum do Cerrado é uma formação aberta formada por árvores e arbustos baixos coexistindo com uma vegetação de gramíneas, entretanto, estão incluídas neste bioma várias outras tipologias vegetais, desde formações florestais até áreas de campos limpos (BRASIL, 1999). É comum encontrar também, ao longo do perfil horizontal da vegetação, áreas rupestres, capões de mata e áreas brejosas (MACHADO et al. 2004).

Ribeiro e Walter (2008) classificam a vegetação do Cerrado em onze diferentes tipos fisionômicos, com base na estrutura, formas de crescimento dominantes, possíveis mudanças estacionais, composição florística e fatores edáficos. A seguir são apresentadas as características gerais de cada uma das fitofisionomias. Para aspectos detalhados, recomenda-se a consulta ao trabalho dos autores.

Mata Ciliar - compreende a vegetação florestal que acompanha os rios de médio e grande porte, cuja vegetação não forma galeria. Dificilmente ultrapassa $100 \mathrm{~m}$ de largura em cada margem do curso d'água e se diferencia da Mata de Galeria devido à composição florística e à semideciduidade. A altura das árvores varia de 20 a $25 \mathrm{~m}$, podendo alcançar mais de $30 \mathrm{~m}$. Ao longo do ano, a cobertura arbórea varia de 50 a $90 \%$;

Mata de Galeria - vegetação florestal que acompanha os rios de pequeno porte e córregos, formando corredores fechados sobre o curso d'água (galerias). A vegetação é perenifólia (sempre-verde) e a altura média do estrato arbóreo varia entre 20 e $30 \mathrm{~m}$, cuja cobertura atinge de 70 a $95 \%$. A Mata de Galeria pode ser ainda classificada como não inundável e inundável, apresentando espécies com adaptações a esses ambientes; 
Mata Seca - formações florestais caracterizadas por diversos níveis de deciduidade durante a estação seca, dependentes das condições físico-químicas do solo e, principalmente, da sua profundidade, não apresentando associação com cursos d'água. Os solos dessas formações normalmente são ricos em nutrientes. Dependendo da queda de folhas no período seco, pode haver três subtipos: Mata Seca SempreVerde, Mata Seca Semidecídua e Mata Seca Decídua. A altura média do estrato arbóreo varia de 15 a $20 \mathrm{~m}$ e a cobertura atinge de 70 a $95 \%$ no período chuvoso, enquanto na estiagem pode ser inferior a $50 \%$;

Cerradão - caracteriza-se como uma formação florestal com aspectos xeromórficos, com estrato arbóreo de altura média variando de 8 a $15 \mathrm{~m}$, com copas contínuas que promovem uma cobertura de 50 a $90 \%$ do solo, sendo comum a presença de espécies que ocorrem no Cerrado sentido restrito;

Cerrado sentido restrito - caracteriza-se por apresentar cobertura arbórea de 20 a $50 \%$, com altura média de 3 a $6 \mathrm{~m}$, composta por árvores de porte baixo, tortuosas e com ramificações irregulares e retorcidas, coexistindo com arbustos e subarbustos esparsos. Geralmente, apresenta evidências de queimadas. Devido à complexidade de fatores condicionantes, podem existir subtipos fisionômicos, sendo os principais: Cerrado Denso, Cerrado Típico, Cerrado Ralo e Cerrado Rupestre;

Parque Cerrado - formação savânica caracterizada pela presença de árvores agrupadas em pequenas elevações do terreno, algumas vezes imperceptíveis, conhecidas como "murundus". A cobertura arbórea atinge de 5 a $20 \%$, com altura média de 3 a $6 \mathrm{~m}$. Os solos desses ambientes podem apresentar hidromorfismo devido ao acúmulo de água e são mais bem drenados nos murundus que nas áreas planas adjacentes;

Palmeiral - formação savânica caracterizada pela presença de uma única espécie de palmeira, com frequência baixa de árvores dicotiledôneas. Em geral, ocorre em terrenos bem drenados, mas pode haver formação também em terrenos brejosos, como aqueles dominados pelas espécies Mauritia flexuosa L. (buriti) ou Mauritia armata Mart. (buritirana);

Vereda - fitofisionomia caracterizada pela presença da palmeira buriti em meio a agrupamentos mais ou menos densos de espécies arbustivo-herbáceas, em solos hidromórficos saturados na maior parte do ano. Os buritis apresentam altura média de 12 a $15 \mathrm{~m}$ e cobertura de 5 a $10 \%$;

Campo Sujo - possui estrutura exclusivamente herbáceo-arbustiva, com arbustos e subarbustos esparsos e indivíduos de espécies do Cerrado sentido restrito menos desenvolvidos. Dependendo de particularidades ambientais, em especial a profundidade do lençol freático, pode haver três subtipos fisionômicos: Campo Sujo Seco, Campo Sujo Úmido e Campo Sujo com Murundus;

Campo Limpo - vegetação exclusivamente herbácea, com arbustos raros e ausência de árvores. O Campo Limpo também apresenta subtipos de acordo com as particularidades ambientais associadas à umidade do solo e à topografia, sendo eles: Campo Limpo Seco, Campo Limpo Úmido e Campo Limpo com Murundus;

Campo Rupestre - formação predominantemente herbáceo-arbustiva, com a presença eventual de arvoretas com até $2 \mathrm{~m}$ de altura. Geralmente, ocorre em altitudes superiores a $900 \mathrm{~m}$, mas pode ocorrer em áreas com altitudes acima de $700 \mathrm{~m}$, agrupando paisagens em microrrelevos com espécies típicas em trechos com afloramentos rochosos. A composição florística pode variar muito em curtas distâncias, cuja densidade varia de acordo com o substrato.

\section{ESTOQUES DE BIOMASSA VEGETAL E A IMPORTÂNCIA NA ARMAZENAGEM DO CARBONO}

São poucos os estudos de determinação da biomassa vegetal em fitofisionomias do Cerrado, em sua maioria relacionados ao Cerrado sentido restrito (Tabela 1). A quantidade de estudos desta natureza pode ser atribuída à dificuldade de mensuração dos seus componentes de biomassa, devido, principalmente, às características das espécies adaptadas a esses ambientes, como a tortuosidade do tronco e a profundidade no solo atingida pelo sistema radicular. 
TABELA 1: Resultados de trabalhos de quantificação de biomassa aérea e subterrânea em diferentes fitofisionomias do bioma Cerrado.

TABLE 1: Results of studies of quantification of aboveground and belowground biomass in different physiognomies of Cerrado biome.

\begin{tabular}{|c|c|c|c|}
\hline Fitofisionomia & Autor(es) & $\begin{array}{c}\text { Biomassa aérea } \\
\left(\mathrm{Mg}^{\left.-h a^{-1}\right)}\right.\end{array}$ & $\begin{array}{c}\text { Biomassa subterrânea } \\
\left(\mathrm{Mg} \cdot \mathrm{ha}^{-1}\right)\end{array}$ \\
\hline $\begin{array}{l}\text { Floresta de } \\
\text { Galeria }\end{array}$ & Santana et al. (2013) & 24,57 & - \\
\hline \multirow{4}{*}{ Cerradão } & Scolforo et al. (2015) & 30,20 & - \\
\hline & Miguel (2015) & 61,21 & - \\
\hline & Santana et al. (2013) & 23,66 & - \\
\hline & Morais et al. (2013) & 36,63 & 7,22 \\
\hline \multirow{10}{*}{$\begin{array}{l}\text { Cerrado sentido } \\
\text { restrito }\end{array}$} & Castro e Kauffman (1998) & 24,80 (aberto) & 46,60 (aberto) \\
\hline & Castro e Kauffman (1998) & 24,90 (denso) & 52,90 (denso) \\
\hline & Vale, Fiedler e Silva (2002) & 12,39 & - \\
\hline & Abdala et al. (1998) & 31,60 & 41,10 \\
\hline & Vale e Felfili (2005) & 12,40 & - \\
\hline & Rezende et al. (2006) & $9,85 \pm 1,08$ & - \\
\hline & Ribeiro et al. (2011) & 62,96 & 37,50 \\
\hline & $\begin{array}{l}\text { Paiva, Rezende e Pereira } \\
(2011)\end{array}$ & 8,60 & 22,38 \\
\hline & Santana et al. (2013) & 16,03 & - \\
\hline & Scolforo et al. (2015) & 56,30 & - \\
\hline \multirow{3}{*}{ Campo Sujo } & Castro e Kauffman (1998) & 9,30 & 30,10 \\
\hline & Santana et al. (2013) & 8,45 & - \\
\hline & Scolforo et al. (2015) & 11,40 & - \\
\hline Campo Limpo & Castro e Kauffman (1998) & 5,50 & 16,30 \\
\hline
\end{tabular}

Nota-se que há um gradiente de biomassa vegetal aérea (troncos, galhos e folhas) entre as diferentes fitofisionomias do bioma, em ordem decrescente das formações florestais para as herbáceo-arbustivas. A razão entre biomassa aérea e subterrânea (raízes) também se modifica com a fitofisionomia, sendo maior para as formações florestais e menor para as formações herbáceo-arbustivas.

Apenas para o Cerrado sentido restrito foi possível se obter uma média para as biomassas aérea e subterrânea, sendo iguais a 25,98 Mg.ha- e 40,09 Mg.ha- ${ }^{-1}$, respectivamente. Para as demais fitofisionomias, calculou-se apenas as médias de biomassa aérea para Cerradão e Campo Sujo, sendo iguais a 37,92 Mg.ha-1 e 9,72 Mg.ha-1 ${ }^{-1}$ respectivamente.

A partir desses estudos, observa-se que a distribuição da biomassa vegetal varia conforme a composição e estrutura da fitofisionomia, assim como a proporção entre biomassa aérea e subterrânea. Observa-se, também, que são necessários mais estudos de determinação da biomassa vegetal em diferentes fitofisionomias, a fim de possibilitar estimativas mais precisas com base na estatística e estrutura e composição da vegetação.

A distribuição da biomassa aérea está relacionada principalmente à presença de indivíduos arbóreos na composição das fitofisionomias, cujos troncos têm maior capacidade de armazenagem do carbono que as raízes (VALE; FELFILI, 2005; DELITTI; MEGURO; PAUSAS, 2006; MORAIS et al., 2013).

A estrutura diamétrica da vegetação pode ser usada para distinguir fitofisionomias (BATALHA; MANTOVANI; MESQUITA JÚNIOR, 2001) e tem relação direta com a estocagem de biomassa e carbono na comunidade, sendo possível, a partir do diâmetro dos indivíduos, obter estimativas desses estoques de meneira mais simples e prática, sem a necessidade de amostragens destrutivas, por meio do ajuste de equações alométricas com técnicas de regressão (REZENDE et al., 2006; DELITTI; MEGURO; PAUSAS, 2006; RIBEIRO et al., 2011; MIGUEL, 2015).

Otoni et al. (2013) observaram que a distribuição de espécies arbóreas no Cerrado ocorre em função das distâncias com os cursos d'água, fertilidade ( $\mathrm{P}, \mathrm{K}$ e Ca) e acidez do solo. Este pode ser uns dos motivos para o pouco número de estudos de determinação de biomassa vegetal em formações florestais, pois normalmente estão associadas a corpos d'água, cujas faixas marginais são protegidas pela legislação brasileira (BRASIL, 2012), sendo este um obstaculo para a realização de amostragens destrutivas. 
De acordo com Meirelles e Henriques (1992), a precipitação é um dos fatores ambientais que mais limita a produtividade da vegetação herbácea em regiões de Cerrados. A relação da produtividade primária com a disponibilidade de água também foi relatada por Marimon Junior e Haridasan (2005), ao verificarem que a textura mais argilosa do solo, por ter maior capacidade de retenção de água e, consequentemente, maior fertilidade, pode favorecer a síntese de biomassa no Cerradão em relação ao Cerrado sentido restrito.

Ademais, a proporção entre a biomassa aérea e a subterrânea se relaciona com as condições mais áridas das formações rupestres e savânicas, cujas espécies adaptadas desenvolvem um sistema radicular mais profundo, que representam a maior parte da biomassa e carbono armazenado na vegatação (ABDALA et al., 1998; CASTRO; KAUFFMAN, 1998; PAIVA; REZENDE; PEREIRA, 2011).

Moreira e Klink (2000) compararam a distribuição de biomassa e crescimento de ramos e raízes entre dez árvores nativas de duas comunidades no Cerrado. No estudo, foram utilizadas três espécies de ocorrência no Cerradão, quatro espécies de ocorrência em Cerrado sentido restrito e três espécies de ocorrência comum nas duas fitofisionomias anteriores. A relação raiz/ramo para uma das espécies do Cerradão foi menor que um, enquanto para uma espécie do Cerrado sentido restrito a relação assumiu o valor de nove. As demais espécies, independentemente da fitofisionomia, tiveram relação raiz/ramo entre um e seis. De acordo com os autores, estes altos valores provavelmente estão relacionados com a estratégia das espécies para resistirem à época seca e rebrotarem após a ocorrência de fogo.

Além da umidade, diversos outros fatores, tanto bióticos como abióticos, influenciam na proporção parte aérea/raiz da vegetação, a exemplo do estágio sucessional, da idade da comunidade, da textura do solo e da disponibilidade de nutrientes (ADUAN; VILELA; KLINK, 2003).

É preciso considerar, também, que as diferentes frações do vegetal (fuste, galhos, casca, folhas e raízes) podem apresentar variações dos teores de carbono na biomassa. A fim de ilustrar, pode ser citado o estudo de Vieira et al. (2009), que observaram teores médios de carbono para espécies do Cerrado nas proporções de $43,24 \%$ para folhagem, $42,06 \%$ para os galhos, $40,09 \%$ para as raízes, $41,02 \%$ para os fustes e $40,60 \%$ para a casca.

Outro componente de armazenagem de carbono no Cerrado é a serapilheira, que está relacionada à sazonalidade (PAROON; BUSTAMANTE; PRADO, 2004; CIANCIARUSO et al., 2006; CAMPOS et al., 2008). Cianciaruso et al. (2006) observaram ao longo de um ano que a massa de serapilheira, composta por folhas, ramos e estruturas reprodutivas, variou de 0,2124 Mg.ha- ${ }^{-1}$. ês $^{-1}$, no mês de fevereiro, para 1,0497 Mg.ha' ${ }^{-1}$.mês ${ }^{-1}$, no mês de julho do mesmo ano, sendo os maiores valores observados nos meses em que os indivíduos entram no estado de dormência, promovendo a abscisão do material vegetativo.

Silva et al. (2007) verificaram que, em um ano, a produção de serapilheira em Cerrado sentido restrito e Cerradão pode chegar a 0,622 Mg.ha- e 1,046 Mg.ha ${ }^{-1}$, respectivamente. Tem-se, também, a contribuição da biomassa de lianas na armazenagem de carbono no Cerrado, que foi estimada em até 9,46 Mg.ha-1 por Carvalho, Bernacci e Coelho (2013).

Por ser de ocorrência natural e fator importante no fluxo de carbono e nutrientes no Cerrado (BUSTAMANTE et al., 2012), a influência do fogo sobre a produtividade primária também foi estudada em áreas de Campo Sujo e/ou compostas apenas por gramíneas, resultando tanto em maior quanto em menor produtividade na área queimada (MEIRELLES; HENRIQUES, 1992; CARDOSO et al., 2000).

De acordo com Kauffman, Cummings e Ward (1994), o comportamento e a severidade do fogo, assim como a perda de nutrientes, são influenciados pelo gradiente de biomassa entre fitofisionomias do Cerrado, uma vez que a composição e estrutura da comunidade diferencia a qualidade e quantidade do material combustível. Além disso, o fogo pode exercer papel relevante na modificação da estrutura da vegetação (FELFILI; SILVA JUNIOR, 1988; LOPES; VALE; SCHIAVINI, 2009).

Ribeiro et al. (2011) reiteram que estudos de quantificação da biomassa nas diferentes fitofisionomias do Cerrado são de grande importância, pois o conjunto tem relevância como reserva de carbono e biodiversidade.

De acordo com Delliti, Pausas e Burger (2001), a expansão agrícola pode alterar o ciclo do carbono nos ecossistemas do Cerrado e afetar a sua capacidade de estocagem de $\mathrm{CO}_{2}$. Neste sentido, os autores afirmam que a biomassa abaixo do solo no Cerrado também deve ser considerada nos estudos de armazenagem do carbono, no efeito do fogo, na mudança do uso do solo e na capacidade de resiliência.

Para Aduan, Vilela e Klink (2003) o maior estoque e, talvez, o mais complexo dos ecossistemas 
terrestres é o do solo, sendo o sistema radicular e a matéria orgânica os componentes que representam os estoques de carbono mais importantes no Cerrado típico (BUSTAMANTE et al., 2012).

Paiva e Faria (2007) verificaram uma supremacia da matéria orgânica do solo na armazenagem do carbono, representando 88,7\% (271,23 Mg.ha $\left.{ }^{-1}\right)$ da quantidade do reservatório abaixo do solo, enquanto

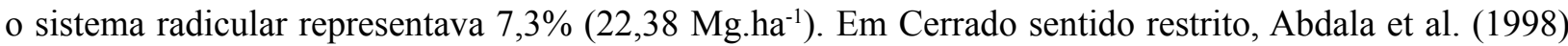
também observaram que o carbono no solo atinge aproximadamente $90 \%$ do total armazenado. Enquanto Morais et al. (2013) verificaram que, no Cerradão, o solo pode representar 64,8\% do carbono total.

A compreensão de todos os potenciais impactos do Cerrado nas mudanças climáticas exige mais informações espaciais e temporais de suas fitofisionomias e sobre as suas interações com as modificações do uso do solo, cujo desconhecimento torna complexas as projeções de impactos em cenários climáticos futuros (BUSTAMANTE et al., 2012).

Uma das vantagens dos estudos de determinação de biomassa e carbono é a possibilidade de associá-los com geotecnologias e dados de sensoriamento remoto e poder fazer estimativas da vegetação em maiores escalas e de forma mais rápida e barata (KUNTSCHIK; BITTENCOURT, 2003; MACHADO et al., 2004; PINHEIRO; DURIGAN, 2009). O uso de estereofotografias também é uma alternativa útil para verificar a biomassa e a estrutura da vegetação, podendo servir para a avaliação do microclima e sequestro de carbono no Cerrado (OTTMAR et al., 2004).

Kuntschik e Bittencourt (2003), por meio de imagens de satélite, encontraram valores médios de biomassa variando de 0,2433 a 120,35 Mg.ha ${ }^{-1} \mathrm{em}$ área de Cerradão, no Oeste do estado de São Paulo, mostrando como pode ser útil o uso dessa ferramenta. Para os autores, as principais causas da variação foram a remoção de indivíduos arbóreos para implantação de pastagens, a proximidade da floresta com áreas úmidas e a declividade do ambiente.

A partir da análise de uma cronossequência de fotos aéreas e imagens de satélite, Pinheiro e Durigan (2009) conseguiram observar a dinâmica de ocupação de áreas por diferentes fitofisionomias e concluíram que a proteção contra o fogo e a suspensão de atividades agropastoris possibilitaram uma evolução gradativa de formações mais abertas para outras mais fechadas, sendo o uso do sensoriamento remoto de utilidade também para estudos da estrutura da vegetação.

A rápida ocupação por atividades produtivas que implicam na supressão da vegetação e mudança do uso do solo, em conjunto com a falta de uma estratégia governamental orientada para a sua sustentabilidade, fez com que grande parte do Cerrado brasileiro fosse devastada, podendo as emissões de dióxido de carbono assumirem valores tão significativos quanto as causadas pelo desmatamento na Amazônia (SAWYER, 2009)

A principal causa para a diminuição da área do Cerrado está atribuída à ocupação humana, devido, principalmente, ao aumento da população em centros urbanos, implantação mecanizada de culturas agrícolas, como a soja, milho, algodão e cana-de-açúcar, e cultivo de pastagens para criação de gado (MACHADO et al., 2004; BRASIL, 2006; 2007; SANO et al., 2008, BRASIL, 2015).

Mantovani e Pereira (1998) verificaram em imagens de satélite que, nos anos de 1992 e 1993, a região dos Cerrados já se encontrava em intensa antropização, com um terço de sua área fortemente modificada. Machado et al. (2004) em imagens MODIS, do ano 2002, calcularam uma área desmatada de $54,9 \%$ da área total do Cerrado, e concluíram que, neste ritmo de ocupação, o bioma será completamente destruído no ano 2030.

Em imagens de satélite, também no ano 2002, Sano et al. (2008) identificaram 80 milhões de hectares da área original do Cerrado sob diferentes usos da terra, o que corresponde a 39,5\% da área total do bioma. Os autores identificaram que os estados de São Paulo, Paraná e Mato Grosso do Sul possuíam os menores índices de cobertura de vegetação natural e os estados da região norte do Cerrado, Piauí, Maranhão e Tocantins, os maiores.

A diferença dos resultados obtidos por Sano et al. (2008) e Machado et al. (2004) decorre do nível de detalhamento das imagens de satélite capturadas por diferentes sensores utilizados no mapeamento, portanto, este é um fator importante a ser considerado nas estimativas de desmatamento para o bioma.

Estimativas mais recentes resultantes do Projeto TerraClass Cerrado, desenvolvido pelo Instituto Nacional de Pesquisas Espaciais (INPE) para o mapeamento do uso e cobertura vegetal no bioma, apontam que o Cerrado no ano 2013, ainda possuía 54,49\% de sua cobertura vegetal original (BRASIL, 2015). 
De acordo com o Ministério da Ciência e Tecnologia (MCT), em 2012, o bioma Cerrado representou $62,0 \%$ do total das emissões de $\mathrm{CO}_{2}$ por Mudanças do Uso da Terra e Florestas nos biomas brasileiros (BRASIL, 2014), mostrando-se como uma importante fonte de carbono à atmosfera. Além disso, caso as modificações do uso do solo continuem implicando em perdas de áreas do Cerrado, os impactos antropogênicos, além de contribuiríem com as emissões dos gases do efeito estufa, podem ocasionar o declínio das precipitações nessas regiões, isto devido à relação de interdependência entre o clima e a vegetação (HOFFMANN; JACKSON, 2000).

\section{ESTRATÉGIAS PARA USO SUSTENTÁVEL}

À medida que a expansão agrícola e industrial avança sobre o Cerrado, são necessárias ferramentas avançadas de sensoriamento remoto e Sistemas de Informações Geográficas (SIG), assim como modelos baseados em processos, para se estimar melhor os impactos das mudanças do uso do solo e realizar projeções dos seus efeitos no sequestro de carbono (BATLLE-BAYER; BATJES; BINDRABAN, 2010).

Kennedy et al. (2016) relatam que o planejamento conjunto de metas econômicas e ambientais em uma escala de paisagem, pode fazer com que o setor agrícola brasileiro expanda a sua produção sem deixar de atender aos requisitos regulatórios, mantendo, assim, a biodiversidade e a prestação dos serviços ecossistêmicos.

Neste sentido, o Zoneamento Ecológico Econômico (ZEE), regulamentado pelo Decreto $\mathrm{n}^{\mathrm{o}}$ 4.297, de 10 de julho de 2002 (BRASIL, 2002), surge como um importante instrumento para o planejamento territorial, a fim de compatibilizar o desenvolvimento socioeconômico com a qualidade ambiental no bioma Cerrado.

Do ponto de vista da proteção ambiental, o Cerrado tem 3,1\% de sua área protegida como Unidades de Conservação de Proteção Integral, enquanto 5,5\% do bioma é protegido como Unidades Conservação de Uso Sustentável (BRASIL, 2016). Conforme o Sistema Nacional de Unidades de Conservação (SNUC), as Unidades de Conservação do grupo de Proteção Integral têm, por objetivo, a preservação da natureza, e as do grupo de Uso Sustentável a compatibilização do uso dos seus recursos naturais com a conservação da natureza (BRASIL, 2000).

O Cerrado ocupa a posição de terceiro bioma brasileiro com a maior área protegida na forma de Unidades de Conservação, contudo, essa área ainda é pouca, se comparada com a soma das áreas protegidas na Amazônia, que totalizam 27,7\% do total do bioma (BRASIL, 2016).

É necessário que seja demonstrada a importância que o Cerrado representa, sendo o conhecimento dos diferentes habitat e ecossistemas fundamental para debater a conservação do bioma, fortalecer e ampliar as áreas protegidas, fazer recomendações para políticas públicas e entender quais os efeitos das modificações da paisagem sobre o regime de queimadas, na hidrologia, na ciclagem e estoque de carbono e, possivelmente, no clima (KLINK; MACHADO, 2005).

Sawyer (2009) cita que, apesar de existirem recursos naturais, trabalho disponível e mercado consumidor no país para incentivar o uso sustentável do Cerrado por agricultores familiares e povos e comunidades tradicionais, as dificuldades interpostas por marcos regulatórios adversos, de caráter fiscal, sanitário ou ambiental, prejudicam os benefícios em termos de produção, segurança alimentar, gastos públicos e qualidade ambiental.

Nos últimos anos, tem-se observado uma valorização nos preços dos produtos não madeireiros do Cerrado, que compreendem diversos mercados, desde alimentícios até medicinais, destacando-se o pequi, como a principal espécie comercializada (AFONSO; ÂNGELO, 2009). Além dessa, diversas outras espécies fornecem produtos e subprodutos, como alimentos, fibras, óleos, medicamentos e materiais para construção, que podem ser utilizados para geração de renda e consumo próprio, com grande importância, principalmente, para os povos e comunidades tradicionais do bioma (FERNANDES et al., 2016).

De acordo com Felfili et al. (2004), faz-se necessário o desenvolvimento de uma economia baseada nas peculiaridades dos ecossistemas do Cerrado, envolvendo o extrativismo, a domesticação e o manejo florestal das diversas espécies nativas, além da adoção de estratégias de marketing dos produtos dessas espécies. Porém, para que esse desenvolvimento regional ocorra, os autores recomendam uma série de procedimentos, como: (i) construção do conhecimento científico sobre a sua biodiversidade; (ii) construção 
de bases para estocagem e manejo das informações sobre a sua biodiversidade; (iii) desenvolvimento de indústrias locais para o processamento dos produtos e agregação de valor; (iv) aplicação das políticas de proteção à biodiversidade; (v) valoração econômica dos produtos com potencial econômico; e (vi) criação de políticas de financiamento de atividades produtivas que contemplem as peculiaridades do extrativismo em seus ecossistemas.

Assim, iniciativas para propiciar o desenvolvimento sustentável no bioma merecem ser incentivadas por meio de políticas públicas, como é o caso do "Programa Cerrado Sustentável" do Ministério do Meio Ambiente, que objetiva a promoção da conservação, restauração, recuperação, manejo sustentável e a valorização e reconhecimento das populações tradicionais do bioma (BRASIL, 2005).

Além dos produtos e subprodutos do Cerrado, o (eco) turismo também se mostra como potencial econômico para a região, devido às suas belezas cênicas naturais, configuradas pelo seu complexo geológico, recursos hídricos e grande biodiversidade que abriga.

Deve-se ressaltar, ainda, a necessidade de valoração econômica (monetária) dos recursos naturais do Cerrado como estratégia para a conservação do bioma, de modo a subsidiar a tomada de decisões de políticas públicas, devido ao custo de oportunidade percebido pela mudança do uso do solo (NOGUEIRA; MEDEIROS; ARRUDA, 2000). Além disso, a valoração monetária pode servir como subsídio para as ações judiciais e extrajudiciais que objetivem a reparação de danos ambientais no bioma, em especial, em áreas protegidas, como Unidades de Conservação, Reserva Legal e Áreas de Preservação Permanente (FREITAS, 2011).

\section{CONSIDERAÇÕES FINAIS}

São poucos os trabalhos referentes à quantificação da biomassa acumulada nas diferentes fitofisionomias do bioma Cerrado, que, em virtude do contexto atual, mais especificamente frente às mudanças climáticas, devem ser estimulados, principalmente pelo grau de devastação que o bioma chegou ao longo dos anos em razão do modelo de desenvolvimento adotado no país.

Em se tratando do impacto causado no aquecimento global pela supressão de quase $50 \%$ da vegetação do bioma, torna-se complexa a mensuração da quantidade de dióxido de carbono já emitida à atmosfera, em virtude da heterogeneidade da estrutura e composição das fitofisionomias que compõem o Cerrado. Para isso, o uso de técnicas de sensoriamento remoto, geoprocessamento e modelagem estatística podem ser alternativas bastante efetivas para avaliação desses impactos, com maior rapidez e menor custo, desde que resultados consistentes sejam obtidos na quantificação em campo para cada situação encontrada.

É válido ressaltar que a contribuição do Cerrado na emissão de gases causadores do efeito estufa não é realizada somente pela mudança do uso do solo, mas também é causada pelo fogo, que atinge o ambiente nas épocas de estiagem em um processo natural. No entanto, o carbono perdido é novamente acumulado no período vegetativo, tendo pouca contribuição para a emissão de gases do efeito estufa em relação às atividades antrópicas exercidas sobre o bioma.

Estudos relacionados à biodiversidade também devem ser estimulados visando à obtenção de dados mais abrangentes sobre o potencial do bioma Cerrado para conservação, além da identificação dos produtos e subprodutos que podem ser obtidos e comercializados das espécies que compõem a vegetação. Somente dando valor (ou agregando-o) ao Cerrado que a sua supressão passará a ser desestimulada, como é o caso da Amazônia e Pantanal, e até mesmo de algumas regiões do Cerrado, que já possuem múltiplos produtos e subprodutos com valor de mercado, incluindo o turismo ecológico (ecoturismo), que pode ser bastante rentável.

Ressalta-se, por fim, a importância de políticas públicas e trabalhos de conscientização voltados para a conservação e sustentabilidade do bioma, considerando os benefícios econômicos e sociais que podem ser obtidos a partir do manejo mais racional dos seus recursos naturais, além daqueles ambientais, como a armazenagem de carbono, que contribui para a mitigação das emissões de gases do efeito estufa. 


\section{REFERÊNCIAS}

ABDALA, G. C. et al. Above and belowground organic matter and root: shoot ratio in a cerrado in central Brazil. Brazilian Journal of Ecology, Rio Claro, v. 2, n. 1, p. 11-23, 1998.

ADUAN, R. E.; VILELA, M. F.; KLINK, C. A. Ciclagem de carbono em ecossistemas terrestres - o caso do cerrado brasileiro. Planaltina: Embrapa Cerrados, 2003. 30 p. (Documentos, 105).

AFONSO, S. R.; ÂNGELO, H. Mercado dos produtos florestais não-madeireiros do Cerrado brasileiro. Ciência Florestal, Santa Maria, v. 19, n. 3, p. 315-326, jul./set. 2009.

ALVIN, P. T. Teoria sobre a formação dos campos cerrados. Revista Brasileira de Geografia, Rio de Janeiro, v. 16, n. 4, 1954.

AREVAlO, L. A.; ALEGRE, J. C.; VILCAHUAMAN, L. J. M. Metodologia para estimar o estoque de carbono em diferentes sistemas de uso da terra. Colombo: Embrapa Florestas, 2002. 41 p. (Documentos, 23).

BATALHA, M. A.; MANTOVANI, W.; MESQUITA JÚNIOR, H. N. Vegetation structure in Cerrado physiognomies in south-eastern Brazil. Brazilian Journal of Biology, São Carlos, v. 61, n. 3, p. 475-483, 2001.

BATLLE-BAYER, L.; BATJES, N. H.; BINDRABAN, P. S. Changes in organic carbon stocks upon land use conversion in the Brazilian Cerrado: a review. Agriculture, Ecosystems and Environment, Amsterdam, v. 137 , p. $47-58,2010$.

BRASIL. Decreto no 4.297, de 10 de julho de 2002. Disponível em: <http://www.planalto.gov.br/ccivil_03/ decreto/2002/d4297.htm>. Acesso em: 15 mar. 2017.

BRASIL. Decreto no 5.577, de 8 de novembro de 2005. Disponível em: <http://www.planalto.gov.br/ ccivil_03/_Ato2004-2006/2005/Decreto/D5577.htm>. Acesso em: 15 mar. 2017.

BRAS̄LL. Lei no 9.985, de 18 de julho de 2000. Disponível em: <http://www.planalto.gov.br/ccivil_03/ leis/L9985.htm>. Acesso em: 15 mar. 2017.

BRASIL. Lei $\mathbf{n}^{\mathbf{0}}$ 12.651, de 25 de maio de 2012. Disponível em: < http://www.planalto.gov.br/ccivil_03/_ ato2011-2014/2012/lei/112651.htm>. Acesso em: 14 mar. 2017.

BRASIL. Ministério da Ciência, Tecnologia e Inovação. Estimativas anuais de emissões de gases efeito estufa no Brasil. 2. ed. Brasília: Ministério da Ciência, Tecnologia e Inovação, 2014.

BRASIL. Ministério do Meio Ambiente. Avaliação e ações prioritárias para a conservação da biodiversidade do cerrado e pantanal. Brasília: Ministério de Meio Ambiente, 1999.

BRASIL. Ministério do Meio Ambiente. Biodiversidade do Cerrado e Pantanal: áreas e ações prioritárias para conservação. Brasília: Ministério do Meio Ambiente, 2007. (Série Biodiversidade, 17).

BRASIL. Ministério do Meio Ambiente. Cadastro Nacional de Unidades de Conservação. Brasília: MMA, 2016. Disponível em: <http://www.mma.gov.br/images/arquivo/80112/CNUC_Agosto\%20-\%20 Biomas\%201.pdf>. Acesso em: 14 mar. 2017.

BRASIL. Ministério do Meio Ambiente. Mapeamento do uso e cobertura do Cerrado: Projeto TerraClass Cerrado. Brasília: Ministério do Meio Ambiente, 2015.

BRASIL. Ministério do Meio Ambiente. Programa Nacional de Conservação e Uso Sustentável do Bioma Cerrado. Brasília: Ministério do Meio Ambiente, Programa Cerrado Sustentável, 2006.

BUSTAMANTE, M. M. C. et al. Potential impacts of climate change on biogeochemical functioning of Cerrado ecosystems. Brazilian Journal of Biology, São Carlos, v. 72, n. 3 suppl, p. 655-671, 2012.

CAMPOS, C. P. A conservação das florestas no Brasil, mudança do clima e o mecanismo de desenvolvimento limpo no Protocolo de Quioto. 2001. 169 f. Dissertação (Mestrado em Ciências em Planejamento Estratégico) - Universidade Federal do Rio de Janeiro, Rio de Janeiro, 2001.

CAMPOS, E. H. et al. Acúmulo de serrapilheira em fragmentos de Mata Mesofítica e Cerrado stricto senso em Uberlândia-MG. Sociedade \& Natureza, Uberlândia, v. 20, n. 1, p. 189-203, jun. 2008.

CARDOSO, E. L. et al. Composição e dinâmica da biomassa aérea após a queima em savana gramíneolenhosa no Pantanal. Pesquisa Agropecuária Brasileira, Brasília, v. 35, n. 11, p. 2309-2316, nov. 2000.

CARVALHO, M. B.; BERNACCI, L. C.; COELHO, R. M. Floristic and phytosociology in a physiognomic gradient of riverine forest in Cerrado, Campinas, SP. Biota Neotropica, Campinas, v. 13, n. 3, p. 110-120, 2013. 
CASTRO E. A.; KAUFFMAN, J. B. Ecosystem structure in the Brazilian cerrado: a vegetation gradient of aboveground biomass, root mass and consumption by fire. Journal of Tropical Ecology, Cambridge, v. 14, p. 263-283, 1998.

CIANCIARUSO, M. V. et al. Produção de serapilheira e decomposição do material foliar em um cerradão na Estação Ecológica de Jataí, município de Luiz Antônio, SP, Brasil. Acta Botânica Brasilica, Belo Horizonte, v. 20, n. 1, p. 49-59, 2006.

COELHO, J. C. Biomassa - Biocombustíveis - Bioenergia. Brasília: Ministério das Minas e Energia, 1982. $100 \mathrm{p}$.

CONSELHO EMPRESARIAL BRASILEIRO PARA O DESENVOLVIMENTO SUSTENTÁVEL. Mecanismo de Desenvolvimento Limpo. Rio de Janeiro: CEBDS, 2002. 31 p. Disponível em: $<\mathrm{http} / /$ www.cebds.org.br/cebds/pub-docs/pub-mc-mdl.pdf>. Acesso em: 6 set. 2011.

CORTE, A. P. D.; SANQUETTA, C. R. Quantificação do estoque de carbono fixado em reflorestamentos de Pinus na área de domínio da floresta ombrófila mista no Paraná. Cerne, Lavras, v. 13, n. 1, p. 32-39, 2007. DELITTI, W. B. C.; PAUSAS, J. G.; BURGER, D. M. Belowground biomass seasonal variation in two Neotropical savannahs (Brazilian Cerrados) with different fire histories. Annals of Forest Science, Paris, v. 58, p. 713-721, 2001.

DELITTI, W. B. C.; MEGURO, M.; PAUSAS, J. G. Biomass and mineralmass in a "cerrado" ecosystem. Revista Brasileira de Botânica, São Paulo, v. 29, n. 4, p. 531-540, 2006.

EITEN, G. The cerrado vegetation of Brazil. The Botanical Review, New York, v. 38, n. 2, p. 201-338, 1972.

FELFILI, J. M. et al. Potencial econômico da biodiversidade do Cerrado: estádio atual e possibilidades de manejo sustentável dos recursos da flora. In: AGUIAR, L. M. S.; CAMARGO, A. J. A. Cerrado: ecologia e caracterização. Planaltina: Embrapa Cerrados, 2004. 249 p.

FELFILI, J. M.; SILVA JUNIOR, M. C. Distribuição dos diâmetros numa faixa de Cerrado na Fazenda Água Limpa (FAL) em Brasília-DF. Acta Botanica Brasilica, Belo Horizonte, v. 2, n. 1-2, p. 85-104, 1988. FERNANDES, G. W. et al. Cerrado: em busca de soluções sustentáveis. Rio de Janeiro: Vertente Produções Artísticas, 2016. 212 p.

FREITAS, C. G. A. Valoração do dano ambiental: algumas premissas. Revista do Ministério Público do Estado de Minas Gerais, Belo Horizonte, nesp, 2011.

HIGUCHI, N. et al. Biomassa da parte aérea da vegetação de floresta tropical úmida de terra-firme da Amazônia Brasileira. Acta Amazônica, Manaus, v. 28, p. 153-165, 1998.

HOFFMANN, W. A.; JACKSON, R. B. Vegetation-Climate feedbacks in the conservation of tropical savanna to grassland. Journal of Climate, Boston, v. 13, p. 1593-1602, 2000.

KAUFFMAN, J. B.; CUMMINGS, D. L.; WARD, D. E. Relationships of fires, biomass and nutrient dynamics along a vegetation gradient in the Brazilian cerrado. Journal of Ecology, London, v. 82, n. 3, p. 519-531, 1994.

KENNEDY, C. M. et al. Optimizing land use decision-making to sustain Brazilian agricultural profits, biodiversity and ecosystem services. Biological Conservation, Amsterdam, v. 204, p. 221-230, 2016.

KLINK, C. A.; MACHADO, R. B. A conservação do cerrado brasileiro. Megadiversidade, Belo Horizonte, v. 1, n. 1 , jul. 2005.

KRUG, T. et al. Emissões de gases do efeito estufa da queima de biomassa no cerrado não antrópico utilizando dados orbitais. Relatório de Referência. Brasília: Ministério de Ciência e Tecnologia, 2006.

KUNTSCHIK, G.; BITENCOURT, M. D. Quantificação de fitomassa florestal aérea de cerrado e cerradão através de imagens orbitais SAR. In: SIMPÓSIO BRASILEIRO DE SENSORIAMENTO REMOTO, 11., 2003, Belo Horizonte. Anais... Belo Horizonte: INPE, 2003. p. 2201-2208.

LARCHER, W. Ecofisiologia vegetal. São Carlos: Rima, 2006. 550 p.

LOPES, N. F.; LIMA, M. G. S. Fisiologia da produção. Viçosa, MG: Ed. UFV, 2015. 492 p.

LOPES, S. F.; VALE, V. S.; SCHIAVINI, I. Efeito de queimadas sobre a estrutura e composição da comunidade vegetal lenhosa do Cerrado sentido restrito em Caldas Novas, GO. Revista Árvore, Viçosa, MG, v. 33, n. 4, p. 695-704, 2009.

MACHADO, F. S. Manejo de produtos florestais não madeireiros: um manual com sugestões para o manejo participativo em comunidades da Amazônia. Rio Branco: PESACRE; CIFOR, 2008. 
MACHADO, R. B. et al. Estimativa de perda da área do cerrado brasileiro. Relatório técnico não publicado. Brasília: Conservação Internacional, 2004.

MARENGO, J. A. Mudanças climáticas globais e seus efeitos sobre a biodiversidade: caracterização do clima atual e definição das alterações climáticas para o território brasileiro ao longo do século XXI. Biodiversidade, Brasília, v. 26, 2006.

MANTOVANI, J. E.; PEREIRA, A. Estimativa da integridade da cobertura vegetal de cerrado através de dados TM/Landsat. In: SIMPÓSIO BRASILEIRO DE SENSORIAMENTO REMOTO, 9., 1998, Santos. Anais... Santos: INPE, 1998. p. 1455-1466.

MARIMON JUNIOR, B. H.; HARIDASAN, M. Comparação da vegetação arbórea e características edáficas de um cerradão e um cerrado sentido restrito em áreas adjacentes sobre solo distrófico no leste de Mato Grosso, Brasil. Acta Botânica Brasilica, Belo Horizonte, v. 19, n. 4, p. 913-926, 2005.

MARTINELLI, L. A. et al. Incertezas associadas às estimativas de biomassa em florestas tropicais. In: SEMINÁRIO EMISSÃO X SEQUESTRO DE $\mathrm{CO}_{2}$ - UMA NOVA OPORTUNIDADE DE NEGÓCIOS PARA O BRASIL, Rio de Janeiro. Anais... Rio de Janeiro: CURD, 1994. p. 197-221.

MEIRELLES, M. L.; HENRIQUES, R. P. Produção primária líquida em área queimada e não queimada de campo sujo de cerrado (Planaltina-DF). Acta Botânica Brasilica, Belo Horizonte, v. 6, n. 2, p. 3-14, 1992. MIGUEL, E. P. Redes neurais artificiais para a modelagem do volume de madeira e biomassa do Cerradão com dados de satélite. Pesquisa Agropecuária Brasileira, Brasília, v. 50, n. 9, p. 829-839, set. 2015.

MORAIS, V. A. et al. Carbon and biomass stocks in a fragment of Cerradão in Minas Gerais state, Brazil. Cerne, Lavras, v. 19, n. 2, p. 237-245, abr./jun. 2013.

MOREIRA, A.; KLINK, C. A. Biomass alocation and growth of tree seedlings from two contrasting brazilian savannas. Ecotropicos, Mérida, v. 13, n. 1, p. 43-51, 2000.

NISHI, M. H. et al. Influência dos créditos de carbono na viabilidade financeira de três projetos florestais. Revista Árvore, Viçosa, MG, v. 29, n. 2, p. 263-270, 2005.

NOGUEIRA, J. M.; MEDEIROS, M. A. A.; ARRUDA, F. S. T. Valoração econômica do meio ambiente: ciência ou empiricismo? Cadernos de Ciências \& Tecnologia, Brasília, v. 17, n. 2, p. 81-115, mai./ago. 2000.

OTONI, T. J. O. et al. Componente arbóreo, estrutura fitossociológica e relações ambientais em um remanescente de Cerradão, em Curvelo-MG. Cerne, Lavras, v. 19, n. 12, p. 201-211, abr./jun. 2013.

OTTMAR, R. D. et al. Stereo photo series for quantifying biomass for the Cerrado vegetation in central Brazil. Floresta, Curitiba, v. 34, n. 2, p. 109-112, mai./ago. 2004.

PAIVA, A. O.; REZENDE, A. V.; PEREIRA, R. S. Estoque de carbono em Cerrado sentido restrito do Distrito Federal. Revista Árvore, Viçosa, MG, v. 35, n. 3, p. 527-538, 2011.

PAIVA, A. O.; FARIA, G. E. Estoque de carbono do solo sob cerrado sentido restrito no Distrito Federal, Brasil. Revista Trópica, Chapadinha, v. 1, n. 1, 2007.

PAIVA, R.; OLIVEIRA, L. M. Fisiologia e produção florestal. 2. ed. rev. ampl. Lavras: Ed. UFLA, 2014. $119 \mathrm{p}$.

PAIXÃO, F. A. et al. Quantificação do estoque de carbono e avaliação econômica de diferentes alternativas de manejo em um plantio de eucalipto. Revista Árvore, Viçosa, MG, v. 30, n. 3, p. 411-420, 2006.

PAROON, L. M.; BUSTAMANTE, M. M. C.; PRADO, C. L. C. Produção e composição química de serrapilheira em um gradiente topográfico em mata de galeria no bioma Cerrado. Planaltina: Embrapa Cerrados, 2004. 23 p. (Boletim de Pesquisa e Desenvolvimento).

PINHEIRO, E. S.; DURIGAN, G. Dinâmica espaço-temporal (1962-2006) das fitofisionomias em unidade de conservação do Cerrado no sudeste do Brasil. Revista Brasileira de Botânica, São Paulo, v. 32, n. 3, p. 441-454, jul./set. 2009.

PRADO, C. H. B. A.; CASALI, C. A. Fisiologia vegetal: práticas em relações hídricas, fotossíntese e nutrição mineral. Barueri: Manole, 2006.

REICHARDT, K.; TIMM, L. C. Solo, planta e atmosfera: conceitos, processos e aplicações. Barueri: Manole, 2012. $500 \mathrm{p}$.

REZENDE, A. V. et al. Comparação de modelos matemáticos para estimativa do volume, biomassa e estoque de carbono da vegetação lenhosa de um cerrado sentido restrito em Brasília, DF. Scientia Forestalis, Piracicaba, n. 71, p. 65-76, 2006. 
RIBEIRO, J. F.; HARIDASAN, M. Comparação fitossociológica de um cerrado denso e um cerradão em solos distróficos no Distrito Federal. In: CONGRESSO NACIONAL DE BOTÂNICA, 35., Manaus. Anais... Manaus: SBB, 1984.

RIBEIRO, J. F.; WALTER, B. M. T. As principais fitofisionomias do bioma Cerrado. In: SANO, S. M. et al. (Ed.). Cerrado: ecologia e flora. Planaltina: Embrapa Cerrado, 2008. v. 1. p. 151-212.

RIBEIRO, S. C. et al. Above and belowground biomass in a Brazilian Cerrado. Forest Ecology and Management, Amsterdam, v. 262, p. 491-499, 2011.

SANO, E. E. et al. Mapeamento semidetalhado do uso da terra do Bioma Cerrado. Notas Científicas. Pesquisa Agropecuária Brasileira, Brasília, v. 43, n. 1, p. 153-156, jan. 2008.

SANQUETTA, C. R. Métodos de determinação de biomassa florestal. In: SANQUETTA, C. R. et al. (Ed.). As florestas e o carbono. Curitiba: [s. n.], 2002. p. 119-140.

SANTANA, O. A. et al. Relação entre o índice de avermelhamento do solo e o estoque de carbono na biomassa aérea da vegetação do Cerrado. Ciência Florestal, Santa Maria, v. 23, n. 4, p. 783-794, out./dez. 2013.

SAWYER, D. Fluxos de carbono na Amazônia e no Cerrado: um olhar socioeconômico. Sociedade e Estado, Brasília, v. 24 n. 1, p. 149-171, jan./abr. 2009.

SCHROEDER, P. Carbon storage potential of short rotation tropical tree plantations. Forest Ecology and Management, Amsterdam, v. 50, p. 31-41, 1992.

SCHUMACHER, M. V.; WISTSCHORECK, R. Inventário de carbono em povoamentos de Eucalyptus spp. nas propriedades fumageiras do sul do Brasil: um estudo de caso. In: SANQUETTA, C. R. et al. Fixação de carbono: atualidades, projetos e pesquisas. Curitiba: Edição do Autor, 2004. p. 111-124.

SCOLFORO, H. F. et al. Spatial distribution of aboveground carbon stock of the arboreal vegetation in Brazilian biomes of Savanna, Atlantic Forest and Semi-arid Woodland. PLoS ONE, San Francisco, v. 10, n. 6, p. e0128781, 2015.

SEIFFERT, M. E. B. Mercado de Carbono e Protocolo de Quioto. 1. ed. São Paulo: Atlas, 2009. 205 p. SILVA, C. J. et al. Produção de serrapilheira no Cerrado e floresta de transição Amazônia-Cerrado do centro-oeste brasileiro. Acta Amazonica, Manaus, v. 37, n. 4, p. 543-548, 2007.

SILVA R. F. et al. Projeção do estoque de carbono e análise da geração de créditos em povoamentos de eucalipto. Revista Árvore, Viçosa, MG, v. 32, n. 6, p. 979-992, 2008.

SOARES, C. P. B.; OLIVEIRA, M. L. R. Equações para estimar a quantidade de carbono na parte aérea de árvores de eucalipto em Viçosa, Minas Gerais. Revista Árvore, Viçosa, MG, v. 26, n. 5, p. 533-539, 2002. SOARES, C. P. B.; LEITE, H. G.; GÖRGENS, E. B. Equações para estimar o estoque de carbono no fuste de árvores individuais e em plantios comerciais de eucalipto. Revista Árvore, Viçosa, MG, v. 29, n. 5, p. 711-718, 2005.

SOARES, M. P. et al. Relationship between edaphic factors and vegetation in savannas of the Brazilian midwest region. Revista Brasileira de Ciência do Solo, Viçosa, MG, v. 39, p. 827-829, 2015.

THIBAU, C. E. Produção sustentada em florestas: conceitos e tecnologias, biomassa energética, pesquisas e constatações. Belo Horizonte: [s. n.], 2000.

VALE, A. T.; FIEDLER, N. C.; SILVA, G. F. Avaliação energética da biomassa do Cerrado em função do diâmetro das árvores. Ciência Florestal, Santa Maria, v. 12, n. 2, p. 115-126, 2002.

VALE, A. T.; FELFILI, J. M. Dry biomass distribution in a cerrado sentido restrito site in central Brazil. Revista Árvore, Viçosa, MG, v. 29, n. 5, p. 661-669, 2005.

VIEIRA, G. et al. Teores de carbono em espécies vegetais da caatinga e do cerrado. Revista Acadêmica: ciências agrárias e ambientais, Curitiba, v. 7, n. 2, p. 145-155, 2009.

WATZLAWICK, L. F. et al. O papel do sensoriamento remoto nos estudos de carbono. In: SANQUETA, C. R. et al. (Ed.). As florestas e o carbono. Curitiba: [s. n.], 2002. p. 215-235. 